\title{
Recent Applications of Molecular Structures at Silicon Anode Interfaces
}

\author{
Chen Fang (D) and Gao Liu *(D)
}

Energy Storage and Distributed Resources Division, Lawrence Berkeley National Laboratory, Berkeley, CA 94720, USA; cfang@lbl.gov

* Correspondence: gliu@lbl.gov; Tel.: +1-510-486-7207

\section{check for}

updates

Citation: Fang, C.; Liu, G. Recent Applications of Molecular Structures at Silicon Anode Interfaces.

Electrochem 2021, 2, 664-676. https:// doi.org/10.3390/electrochem2040041

Academic Editor: Masato Sone

Received: 8 November 2021

Accepted: 6 December 2021

Published: 18 December 2021

Publisher's Note: MDPI stays neutral with regard to jurisdictional claims in published maps and institutional affiliations.

Copyright: (c) 2021 by the authors. Licensee MDPI, Basel, Switzerland. This article is an open access article distributed under the terms and conditions of the Creative Commons Attribution (CC BY) license (https:// creativecommons.org/licenses/by/ $4.0 /)$.

\begin{abstract}
Silicon (Si) is a promising anode material to realize many-fold higher anode capacity in nextgeneration lithium-ion batteries (LIBs). Si electrochemistry has strong dependence on the property of the $\mathrm{Si}$ interface, and therefore, Si surface engineering has attracted considerable research interest to address the challenges of $\mathrm{Si}$ electrodes such as dramatic volume changes and the high reactivity of $\mathrm{Si}$ surface. Molecular nanostructures, including metal-organic frameworks (MOFs), covalent-organic frameworks (COFs) and monolayers, have been employed in recent years to decorate or functionalize $\mathrm{Si}$ anode surfaces to improve their electrochemical performance. These materials have the advantages of facile preparation, nanoscale controllability and structural diversity, and thus could be utilized as versatile platforms for $\mathrm{Si}$ surface modification. This review aims to summarize the recent applications of $\mathrm{MOF}$, $\mathrm{COFs}$ and monolayers for $\mathrm{Si}$ anode development. The functionalities and common design strategies of these molecular structures are demonstrated.
\end{abstract}

Keywords: silicon; lithium-ion battery; metal-organic frameworks; covalent-organic frameworks; monolayers

\section{Introduction}

Mobile power systems have become fundamental components in the operation of modern society. Lithium-ion batteries (LIBs) are the most attractive solution for powering up portable digital devices as well as electric vehicles [1,2]. Nevertheless, due to the fast-increasing demand of battery energy density, conventional LIBs constructed with graphite anodes could hardly meet the future requirements of the energy storage market [3]. Consequently, significant efforts have been devoted to the development of next-generation rechargeable batteries. For example, lithium-sulfur (Li-S) batteries have received considerable research interest due to the high specific capacity of sulfur, which is close to five times as that of graphite [4-6]. Yet, practically, the capacity of Li-S battery is often significantly suppressed by a series of problems such as polysulfide dissolution, shuttle phenomenon and anode fading [7-9]. To achieve the highest energy density, LIBs with silicon (Si) anodes could be a competitive candidate. Si has an impressive theoretical capacity of $3579 \mathrm{mAh} \mathrm{g}^{-1}$, and thus Si could possibly improve the anode capacity of current LIBs by about ten-fold $[10,11]$. In addition, the electrochemical set up of Si anodes in LIBs is very similar to that of the commercialized graphite anodes, where $\mathrm{Si}$ and graphite could share the same electrolyte system and cell fabrication protocols and could also be employed in combination $[12,13]$. Therefore, LIBs with Si-based anode materials are promising in fast commercialization [14].

The successful release of the full energy potential of Si anodes in LIBs is still hindered by a few factors. Si anode accommodates lithium with alloying mechanism, leading to major structural changes of Si materials with a reversible volume expansion of over threefold [15]. The repeated large volume fluctuation of Si during electrochemical cycling is the most outstanding issue, and it could lead to Si pulverization $[15,16]$. Other problems could also arise from volume change, including the loss of electrical contact of Si materials and extensive electrolyte consumption due to continuous exposure of new Si interface [16-18]. 
Therefore, it is essential to minimize the impacts of Si volume variation [19]. Nano Si materials such as Si nanowires have been developed to resist alloying-induced electrode cracking as the nanowires could form a porous medium to tolerate Si expansion [15,20]. In addition, tuning the electrochemistry at the Si electrode interface, especially the formation and growth of solid electrolyte interphase (SEI), is also a critical research topic for Si-based LIBs [21-24]. Sophisticated nanostructures and binder systems have been developed to serve these purposes and thus to improve the performance of Si anodes [25-31]. However, the synthetic complexity of these nano materials and structures could very possibly bring significant challenges in actual large-scale application. Moreover, Si materials have low conductivity and sluggish ion diffusion properties in lithiation and delithiation processes, and thus, silicon has been incorporated into carbonaceous matrices or mixed into carbon materials to improve the kinetic properties of $\mathrm{Si}$, although at the sacrifice of the theoretical capacity of the electrode materials $[20,32,33]$.

Molecular structures fabricated in a bottom-up manner are attractive alternatives for engineering Si electrodes. Such materials include metal-organic frameworks (MOFs), covalent-organic frameworks (COFs) and monolayers, which could be readily prepared in a self-organized manner, often under relatively mild conditions or via spontaneous reactions [34-36]. These types of materials have well-defined molecular structures and thus two-dimensional (2D) or three-dimensional (3D) nano-ordered configurations. They provide a versatile platform for the rational engineering of $\mathrm{Si}$ electrodes with wide tunability and nano precision. One of the main applications of the molecular structures is the modification of the $\mathrm{Si}$ anode interface. Despite the vast structural differences of various $\mathrm{Si}$ anodes, they always observe the formation of SEI layers on electrode surfaces, which could play critical roles in determining the long-term cycling stability of the cells. Therefore, developing interface engineering strategies could potentially provide universal solutions for enhancing SEI properties or creating artificial SEIs in numerous Si anodes without changing their existing configuration. The relatively simple preparation of molecular structures at $\mathrm{Si}$ anode surfaces could also be a key benefit for their practical application. In this review, the recent progresses of $\mathrm{Si}$ anode surface structures constructed by MOF, COF and monolayers are summarized. Detailed descriptions of each material are provided in the corresponding sections, along with their properties and applications.

\section{Metal-Organic Framework}

Metal-organic frameworks (MOFs) are a class of networks sustained by the coordination bonding between metal ions (nodes) and organic molecule linkers (ligands) [37]. By using various combinations of metal and linkers, tens of thousands of MOFs have been developed [38]. Due to the diversity of MOF structures, these materials have been employed for various types of applications such as gas storage, separation, biomedical imaging, drug delivery, catalysis, proton conduction and energy storage [38-40]. The common advantageous properties of MOFs include high surface area, nanoscale porosity, controllable pore structure and wide structure tunability [38,41,42]. These features allow MOFs to be incorporated as functional materials in rechargeable batteries.

Han et al. [43] reported the application of MOF as a protective cushion on the $\mathrm{Si}$ anode. The electrodes were fabricated with a simple sandwich-coating method and presented a layered structure at the anode side with the configuration of $\mathrm{Cu}$ foil, conductive carbon, Si and a separator (Figure 1a). With micro-sized Si and ZIF-8 framework (zinc 2-methylimidazolate), the areal capacity reached $1.7 \mathrm{mAh} \mathrm{cm}^{-2}$ and presented a slower decay trend (from about 1.7 to $0.85 \mathrm{mAh} \mathrm{cm}^{-2}$ after 50 cycles) compared to pristine micro-Si (from about 1.3 to $0.05 \mathrm{mAh} \mathrm{cm}^{-2}$ over 20 cycles). The nano-Si/ZIF-8 electrode delivered enhanced cycling stability at $0.6 \mathrm{mAh} \mathrm{cm}^{-2}$ with minor decay over 100 cycles (Figure $1 \mathrm{~b}$ ). By examining a series of other MOFs, it was found that flexible MOFs (MIL-53 and $\mathrm{NH}_{2}-$ MIL-53) or small-aperture MOFs (ZIF-8, ZIF-67) could more effectively help to improve the cycling stability of $\mathrm{Si}$ in comparison to open-channel MOFs (MOF-5, HKUST-1). It was argued that the MOF cushion served to isolate the bulk electrolyte from the Si anode but 
still allowed fast $\mathrm{Li}^{+}$ion diffusion by holding electrolyte in its porous structure. In another work, silica was coated on ZIF-8 as sacrificial template to create inner void spaces in the final mesoporous silicon hollow nano cubes (by magnesiothermic reduction to convert silica to $\mathrm{Si}$ ) [44]. Such thin $\mathrm{Si}$ shells could self-accommodate its volume expansion with internal voids, shorten electronic and ionic pathways and improve electrolyte penetration with the porous structure. A long-term cycling capacity of $850 \mathrm{mAh} \mathrm{g}^{-1}$ after 800 cycles was maintained.

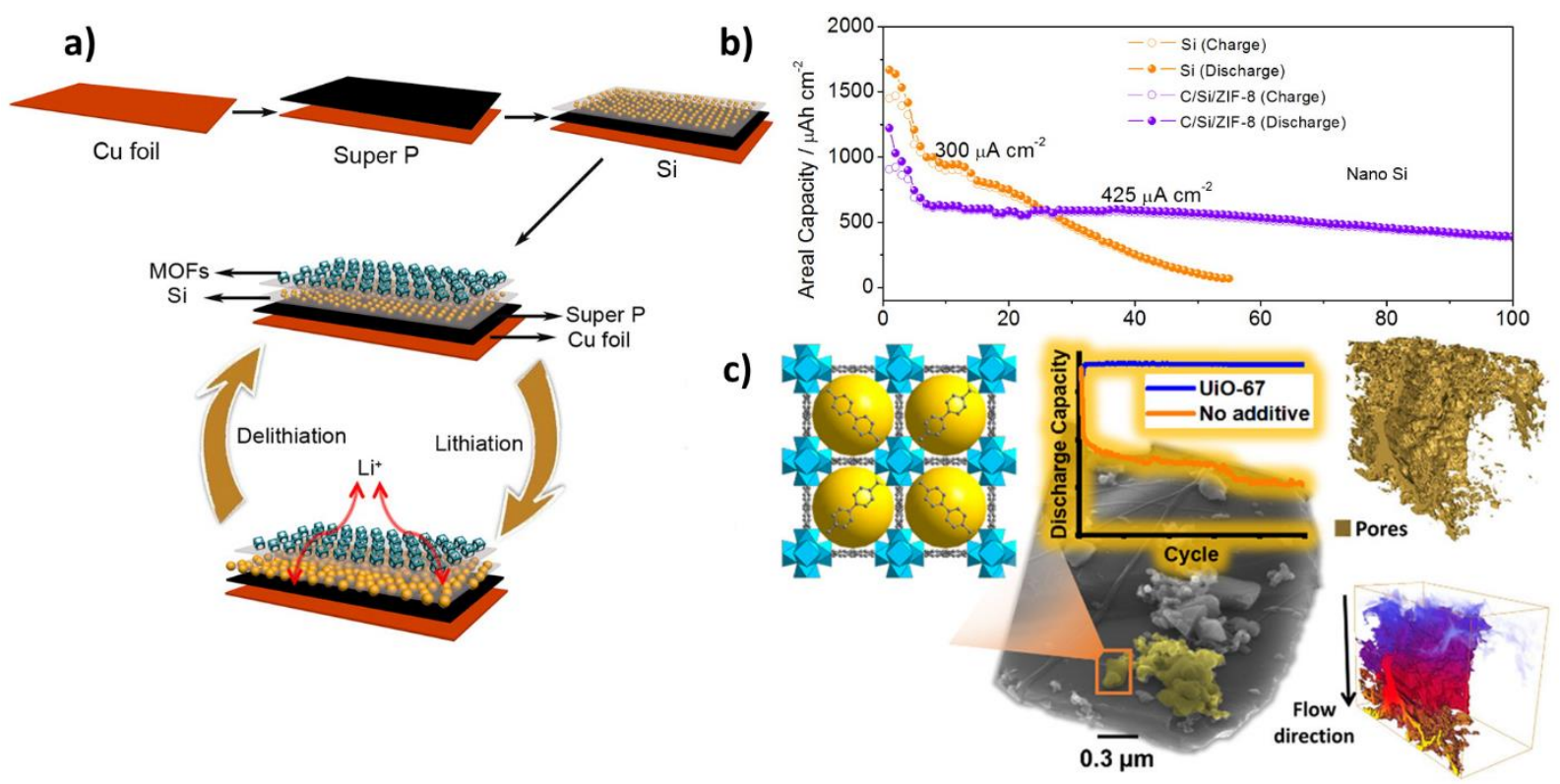

Figure 1. (a) Schematic presentation of MOF/Si/Super P electrodes. (b) Cycling performance of C/Si/ZIF-8 (nano-Si) electrode in comparison with pure Si electrode. (a,b) Reprinted with permission from Ref. [43]. Copyright 2015 American Chemical Society. (c) The cage-like UiO-67 structures on $\mathrm{Si}$ anode form a stable and flexible porous network to facilitate $\mathrm{Li}$ ion flux, thus leading to enhanced cell performance and mitigated anode degradation. Reprinted with permission from Ref. [45]. Copyright 2019 American Chemical Society.

Si could be incorporated with MOF during the electrode composite preparation process as well. Malik et al. [45] used MOF as a porosity-enhancing additive in a Si electrode. In their work, the pre-synthesized UiO-67 (zirconium 4,4'-Biphenyldicarboxylate) was directly incorporated into the electrode material slurry of $\mathrm{Si}$, carbon and binder, followed by blade casting to produce the electrode sheet. It was proposed that the UiO-67 framework could generate a flexible pore network to facilitate $\mathrm{Li}^{+}$flux throughout the electrode, release the tortuosity induced by $\mathrm{Si}$ volume change, and provide extra capacity as a lithium host (Figure 1c). The UiO-67 additive helped the Si electrode to achieve capacity retention that was a few times higher than that of the non-additive electrode.

Park et al. recently reported a composite anode of Si nanoparticles and 2D porous conductive $\mathrm{Ni}_{3}(2,3,6,7,10,11 \text {-hexaiminotriphenylene })_{2} \mathrm{MOF}\left(\mathrm{Si} / \mathrm{Ni}_{3}(\mathrm{HITP})_{2}\right)$ prepared by grinding the mixture of the pre-synthesized $\mathrm{Si}$ and $\mathrm{Ni}_{3}(\mathrm{HITP})_{2}$ materials together [46]. The Si $/ \mathrm{Ni}_{3}(\mathrm{HITP})_{2}$ composite delivered a good capacity of $2657 \mathrm{mAh} \mathrm{g}^{-1}(0.1 \mathrm{C})$ after 100 cycles and also maintained a reversible capacity of $876 \mathrm{mAh} \mathrm{g}^{-1}$ (1C) after 1000 cycles. It was proposed that the MOF facilitated $\mathrm{Li}^{+}$movement with the innate open channels and mitigated $\mathrm{Si}$ volume expansion as well. The same group also reported $\mathrm{Cu}_{3}(\mathrm{HITP})_{2} \mathrm{MOF}$ grown in situ on $\mathrm{Si}$ nanoparticles via a simple solution process for $\mathrm{Si}$ anode applications, where the $\mathrm{Cu}_{3}(\mathrm{HITP})_{2}$ minimized $\mathrm{Si}$ volume changes and particle pulverization to deliver a capacity of $1039 \mathrm{mAh} \mathrm{g}^{-1}$ (1C) after 1000 cycles [47].

MOFs have also been employed for engineering Si nanorod electrodes. Yu et al. described TiN/Ti/Si nanorod (NR) arrays with embedded ZIF-8 nanoparticles as anodes in micro-LIBs [48]. The ZIF-8 coating was formed by solution growth without pyrolysis. 
With hindered SEI formation, improved lithiation properties and mitigated Si volume expansion, this Si nanorod anode realized a capacity of about $1.65 \mathrm{mAh} \mathrm{cm}^{-2}$ with good Coulombic efficiency (CE) of about 99\%. Similarly, metal-organic segments (MOSs) on Si nanorod arrays have been reported for LIB applications [49]. MOS could inhibit SEI formation around $\mathrm{Si}$ nanorod surface and restrict Si volume expansion, thus improving Si anode performance.

Another major application of MOFs is to serve as nano-structured precursors for the generation of favored carbon coatings on the Si anode surface. Bai et al. [50] developed 3D cage-like Si@ZIF-67 silicon electrode materials with one-step liquid phase preparation of the active materials followed by thermal treatment at $600{ }^{\circ} \mathrm{C}$. In the liquid phase preparation, the dodecahedral ZIF-67 (cobalt 2-methylimidazole) shell was formed on the surface of a 20-nanometer Si core to deliver a mesoporous core-shell nanostructure, and the subsequent thermal treatment led to the formation of a carbon layer on Si and produced abundant pores with average size of about $4 \mathrm{~nm}$. Consequently, the composite presented good electrical conductivity as well as fast $\mathrm{Li}^{+}$transport capability. This MOF-derived coating allowed the $\mathrm{Si}$ active materials to maintain good capacities of $1230 \mathrm{mAh} \mathrm{g}^{-1}$ (after 200 cycles) and $1180 \mathrm{mAh} \mathrm{g}^{-1}$ (after 400 cycles) at the rates of 0.5 and $1 \mathrm{~A} \mathrm{~g}^{-1}$, respectively. Another report also employed ZIF-67 for embedding Si nanoparticles with similar solution-based preparation [51]. The obtained Si@ZIF-67 material was carbonized by annealing at $800{ }^{\circ} \mathrm{C}$, which generated Si composite materials with Si particles encapsulated in carbon shell (Si@c-ZIF). Like that in the previous example, Si@c-ZIF could also promote electrical conduction across the interface and allow efficient $\mathrm{Li}^{+}$diffusion along the abundant pores (1 to $4 \mathrm{~nm}$ ). Si@c-ZIF exhibited reversible capacities of $820 \mathrm{mAh} \mathrm{g}^{-1}$ after 1000 cycles at $5 \mathrm{~A} \mathrm{~g}^{-1}$. The good performance was attributed to the MOF-derived carbon shell as buffer to accommodate $\mathrm{Si}$ volume change and also to the good $\mathrm{Li}^{+}$transportation property of the shell enabled by the pores. Li et al. [52] employed a similar strategy and prepared $\mathrm{N}-$ and Co-doped hollow-structured Si/C composite (Si@Co-NC) with Si@ZIF-67 precursor, which delivered a reversible capacity of $191 \mathrm{mAh} \mathrm{g}^{-1}$ at $1 \mathrm{~A} \mathrm{~g}^{-1}$ after 3000 cycles. Jin et al. [53] pyrolyzed Si@ZIF-67 under a hydrogen atmosphere, which led to the formation of metallic Co that catalyzed the conversion of organic residual units of the collapsed ZIF-67 network into carbon nanotubes (CNTs). The obtained Si@N-doped CNTs delivered $1144 \mathrm{mAh} \mathrm{g}^{-1}$ capacity at $1 \mathrm{~A} \mathrm{~g}^{-1}$ over 750 cycles.

Liu et al. also selected ZIF-67 to encapsulate Si materials, but with phenolic resinprecoated Si nanoparticles [54]. Carbonization was performed at $800{ }^{\circ} \mathrm{C}$ under a nitrogen atmosphere to obtain the mesoporous yolk-shell composite Si@C@ZIF-67-800N. The resin and the MOF formed double carbon coating, which helped to deliver reversible capacities of $1107 \mathrm{mAh} \mathrm{g}^{-1}$ at $0.5 \mathrm{~A} \mathrm{~g}^{-1}$ after 100 cycles and $852 \mathrm{mAh} \mathrm{g}^{-1}$ at $1 \mathrm{~A} \mathrm{~g}^{-1}$ over 300 cycles. Qiao et al. reported the decoration of Si nanoparticles with CNTs, which assisted their subsequent encapsulation in ZIF-67 [55,56]. After pyrolysis, the obtained Si@CNTs@cZIF composite delivered a capacity of $568.8 \mathrm{mAh} \mathrm{g}^{-1}$ at $1 \mathrm{~A} \mathrm{~g}^{-1}$ after 200 cycles $(60.1 \%$ retention) [55].

The other ZIF-type framework that has been widely studied as a carbon coating precursor on Si is ZIF-8. Han et al. developed Si@ZIF-8 composite prepared with one-spot mechanochemical synthesis by grinding the ZIF-8 starting materials with Si nanoparticles upon the addition of solvent initiator [57]. The obtained composite was further processed with simple pyrolysis at $700{ }^{\circ} \mathrm{C}$ over a period of $1 \mathrm{~h}$ under nitrogen (for carbonization) to yield the final electrode material Si@ZIF-8-700N (Figure 2). This anode material delivered specific capacity up to $1050 \mathrm{mAh} \mathrm{g}^{-1}$ and also exhibited good reversible capacity of $830 \mathrm{mAh} \mathrm{g}^{-1}$ after 500 cycles at $0.2 \mathrm{~A} \mathrm{~g}^{-1}$ (minor capacity fading observed). The proposed factors leading to the favorable cell performance include carbonized MOF coating mitigating Si volume change, metal centers (from MOF) improving conductivity and storage capacity, and open channels in the matrix facilitating $\mathrm{Li}^{+}$transport. A similar nano-Si@ZIF-8 composite was reported by Song et al. [58], where ZIF-8 was grown on benzoic acid-functionalized nano-Si. Subsequent pyrolysis was performed at $550{ }^{\circ} \mathrm{C}$, and 
the nano-Si/C composites showed specific capacity of $1168 \mathrm{mAh} \mathrm{g}^{-1}$ after 100 cycles at $0.1 \mathrm{~A} \mathrm{~g}^{-1}$. Wei et al. [59] employed ZIF-8 to prepare a spongy carbon matrix to anchor sac-like silicon materials as $\mathrm{Si}$ anodes. The carbon matrix could maintain a stable reaction interface and good electrical conductivity, and it could also buffer the Si volume change. The synthesized composite contained about $77 \%$ active Si materials, and delivered good capacities of 1448 and $848 \mathrm{mAh} \mathrm{g}^{-1}$ at 2 and $4 \mathrm{~A} \mathrm{~g}^{-1}$, respectively, after 500 cycles.
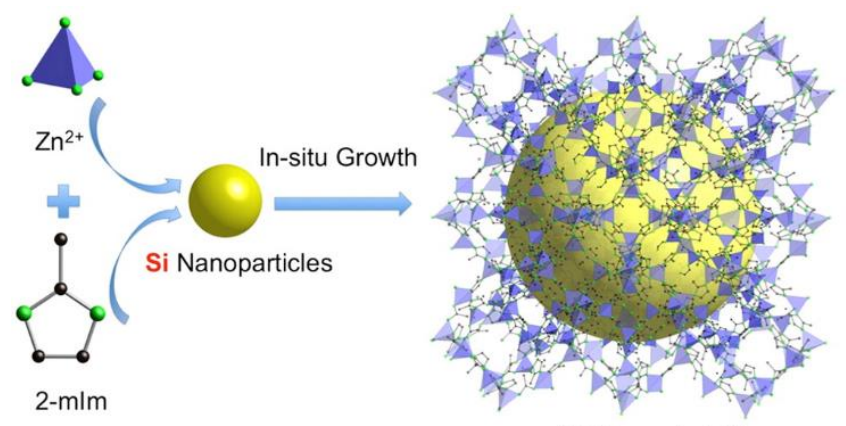

ZIF-8-coated Si

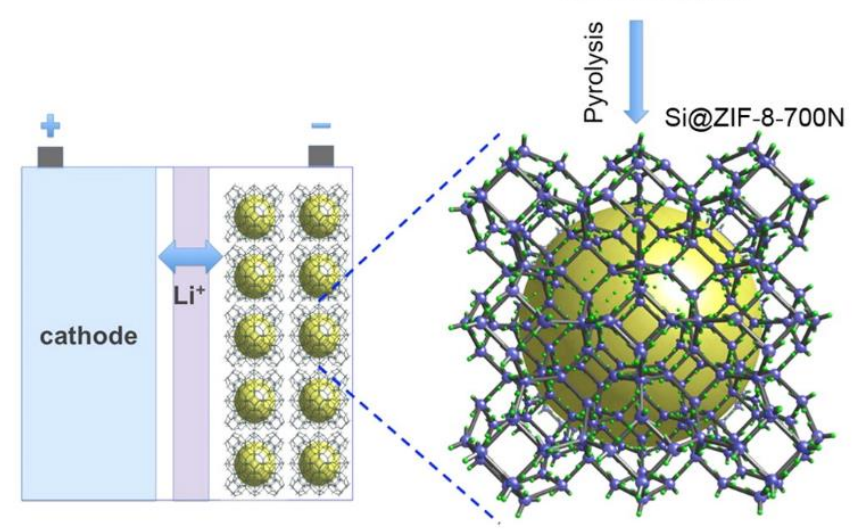

Figure 2. Schematic depiction of ZIF-8 formation on Si surface and subsequent pyrolysis to yield Si@ZIF-8-700N electrode material with amorphous carbon. Color code: carbon, black; nitrogen, green; zinc, blue; silicon, yellow. Reprinted with permission from Ref. [57]. Copyright 2015 American Chemical Society.

MOFs have been applied to a series of silicon oxide materials as well. To address the $\mathrm{Si}$ volume change issue, Wei et al. [60] applied a silica sacrificial template layer over $\mathrm{Si}$ nanoparticles before their encapsulation with ZIF-8, which could eventually be removed by HF after thermal treatments. This strategy allowed the formation of extra empty buffer space around Si nanoparticles and incorporated a high Si content of $71 \mathrm{wt} \%$. This $\mathrm{Si} / \mathrm{C}$ material presented a good rate performance of 1155 and $815 \mathrm{mAh} \mathrm{g}^{-1}$ at 2 and $5 \mathrm{~A} \mathrm{~g}^{-1}$, respectively, and also maintained 1109 and $804 \mathrm{mAh} \mathrm{g}^{-1}$ at 3 and $5 \mathrm{~A} \mathrm{~g}^{-1}$, respectively, after 500 cycles. Majeed et al. [61] directly employed silica to fabricate a $\mathrm{Si}$ anode with ZIF. In this work, $\mathrm{SiO}_{2}$ nanospheres were uniformly covered with $\mathrm{Zn} / \mathrm{Co}-\mathrm{ZIFs}$ as coating precursor, and the subsequent magnesiothermic reduction simultaneously carbonized the ZIF layer and transformed $\mathrm{SiO}_{2}$ to $\mathrm{Si}$. The remaining $\mathrm{MgO}$ could be removed by etching to yield the final mesoporous $\mathrm{Si} / \mathrm{SiO}_{\mathrm{x}}$ nanospheres with a N-doped carbon coating, which exhibited about $700 \mathrm{mAh} \mathrm{g}^{-1}$ capacity after 100 cycles. $\mathrm{SiO}_{\mathrm{x}}$ anode materials have also been decorated with ZIF-67 [62], and simple solution-based precursor preparation and annealing protocols were employed to yield a Co-containing N-doped carbon-coated $\mathrm{SiO}_{\mathrm{x}}\left(\mathrm{SiO}_{\mathrm{x}} @ \mathrm{CoC}\right)$ composite, which delivered $900 \mathrm{mAh} \mathrm{g}^{-1}$ at $1.0 \mathrm{~A} \mathrm{~g}^{-1}$ after 350 cycles. Similarly, the carbonization of $\mathrm{ZIF}(\mathrm{Zn}, \mathrm{Co})$ was performed to prepare a $\mathrm{SiO}$ anode with improved cycling performance [63].

Wang et al. developed a self-sacrificing template strategy with $\mathrm{Si}-\mathrm{Al}$ alloy as the starting material to fabricate Si anodes [64]. 1,4-naphthalic acid was used to etch the 
$\mathrm{Si}-\mathrm{Al}$ alloy microspheres, where the produced $\mathrm{Al}^{3+}$ ions could then form Al-MOF with the organic acid on the $\mathrm{Si}-\mathrm{Al}$ particles. The $\mathrm{Al}$ elements could eventually be removed by etching to create porous Si structures, while the Al-MOF could generate carbon coating upon thermal treatment. The obtained anode materials presented a reversible capacity of $1027.8 \mathrm{mAh} \mathrm{g}^{-1}$ at the rate of $1 \mathrm{~A} \mathrm{~g}^{-1}$ over 500 cycles (79\% retention).

Another MOF used for Si anodes is Prussian blue analogues (PBAs) [65], where the PBA-derived carbon coating helped the $\mathrm{Si}$ nanocomposite to present a reversible capacity of $725 \mathrm{mAh} \mathrm{g}^{-1}$ after 200 cycles. MIL-88-Fe MOF (iron terephthalate) has also been applied to Si nanoparticles' surface as a precursor to produce $\mathrm{Si@Fe}{ }_{2} \mathrm{O}_{3} / \mathrm{C}$ composite upon annealing [66]. The $\mathrm{Fe}_{2} \mathrm{O}_{3} / \mathrm{C}$ coating served to improve conductivity, SEI stability and electrode cycling stability. Xu et al. [67] reported the porous double-shell Si electrode material Si/Ag@PM@MIL-100. The inner shell was made of porous carbon nanosheets and multi-walled carbon nanotubes (PM), which could buffer the large volume expansion of $\mathrm{Si}$ upon lithiation and prevent $\mathrm{Si}$ particle pulverization. The inner shell and the nano-Ag particles served to maintain good electrical contact of Si materials. The outer shell based on MIL-100 framework (iron 4,5-imidazole dicarboxylate) could promote the generation of a stable SEI layer. The highly porous double shell structure allowed rapid $\mathrm{Li}^{+}$transportation. At the rate of $1 \mathrm{~A} \mathrm{~g}^{-1}$, the Si/Ag@PM@MIL-100 electrode delivered a specific capacity of $615 \mathrm{mAh} \mathrm{g}^{-1}$ after 500 cycles with a retention rate of $62.9 \%$. In comparison, the Si electrode prepared without MIL-100 framework presented significantly lower capacity in long-term cycling.

\section{Covalent Organic Frameworks}

Covalent organic frameworks (COFs) are a class of organic molecule-based networks that are similar to MOFs but do not contain metal nodes. COF networks are commonly interconnected by stable covalent bonding and bear conjugated structures [34]. COFs also have the properties of porous structures and high surface areas like MOFs [68]. COFs often have good structural rigidity and could thus be used as protective layers with good mechanical properties on electrodes [69].

Ai et al. [70] developed a lithium-conducting COF coating on Si nanoparticles as an artificial SEI layer, which served to inhibit electrolyte decomposition and thus to improve the cycling stability of the $\mathrm{Si}$ electrode. The COF layer was constructed on $\mathrm{Si}$ particles via solvothermal polymerization between 1,3,5-triformylphloroglucinol (Tp) and 1,4-phenylenediamine-2-sulfonic acid $\left(\mathrm{Pa}_{-} \mathrm{SO}_{3} \mathrm{H}\right)$, followed by a $\mathrm{Li}^{+}$ion exchange at the $\mathrm{R}-\mathrm{SO}_{3} \mathrm{H}$ groups to realize the $\mathrm{Li}^{+}$-conducting property of the network (Figure 3a). Cyclic voltammetry $(\mathrm{CV})$ measurement showed no outstanding electrolyte reduction peak of the Si@COF electrode, confirming the effective protection of Si particles by COF. Consequently, Si@COF presented significantly higher cycling performance than pristine $\mathrm{Si}$ at $1 \mathrm{~A} \mathrm{~g}^{-1}$. Due to the lithium conducting properties, this COF network could facilitate $\mathrm{Li}^{+}$ transportation throughout the $\mathrm{Si}$ active materials and thus allowed good rate performances of 2761 and $962 \mathrm{mAh} \mathrm{g}^{-1}$ at 0.5 and $5 \mathrm{~A} \mathrm{~g}^{-1}$, respectively, with about full reversibility when restored to $0.5 \mathrm{~A} \mathrm{~g}^{-1}$ (Figure $3 \mathrm{~b}$ ). In the long-term cycling test, the Si@COF anode delivered $1864 \mathrm{mAh} \mathrm{g}^{-1}$ capacity at a high rate of $2 \mathrm{~A} \mathrm{~g}^{-1}$ after 1000 cycles with a retention ratio of about $60 \%$ (Figure 3c). These results demonstrate that COF coating is an effective strategy to protect $\mathrm{Si}$ materials to reduce electrolyte decomposition and SEI formation, and thus to realize good electrochemical performance of $\mathrm{Si}$ anodes. 
(a)

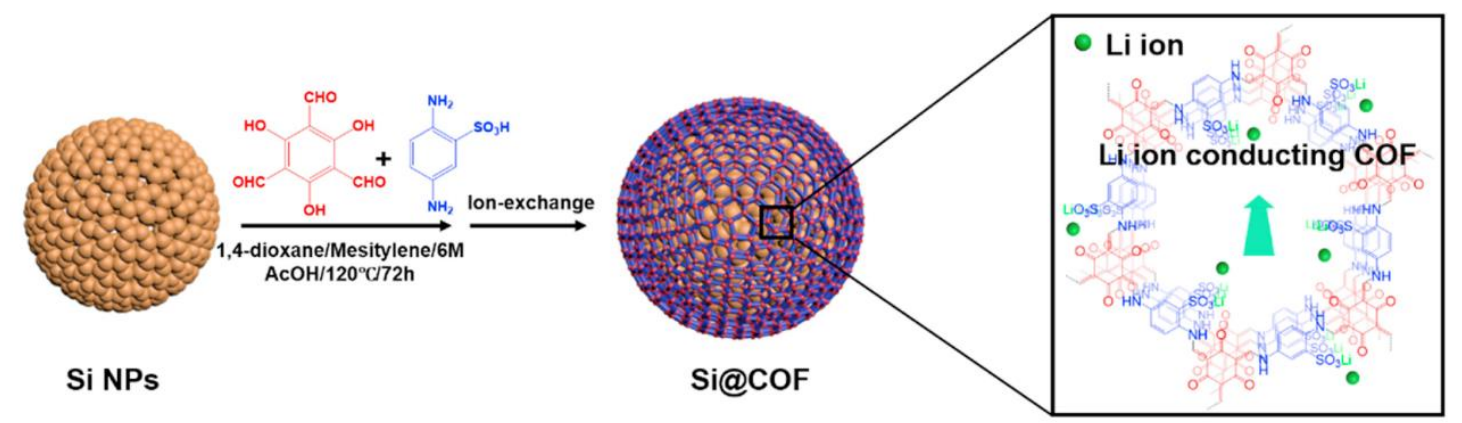

(b)

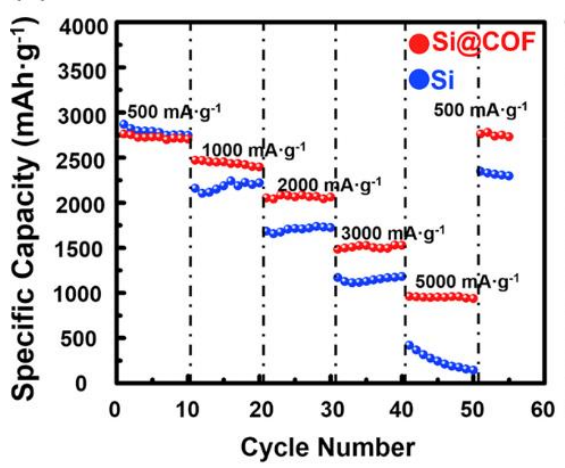

(c)

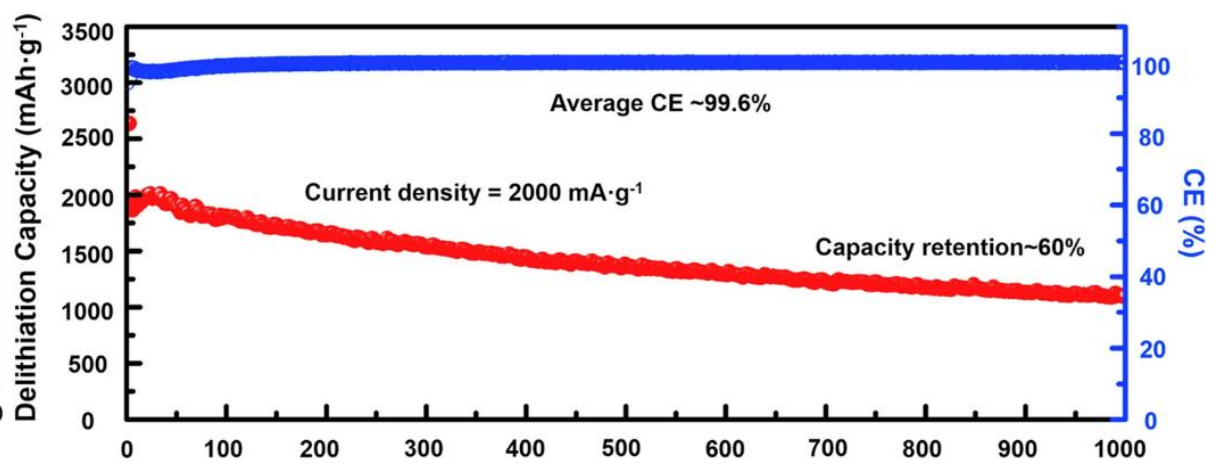

Figure 3. (a) Schematic depiction of Si@COF synthesis. (b) Rate performance of pristine Si versus Si@COF. (c) Long-term cycling of Si@COF $\left(2 \mathrm{~A} \mathrm{~g}^{-1}\right)$. (a-c) Reprinted with permission from Ref. [70]. Copyright 2020 Elsevier.

COF-type materials could also be utilized as precursors of carbon coating on $\mathrm{Si}$ materials. Zhou et al. [71] reported the trimerization of $p$-benzenedinitrile to produce porous covalent triazine framework (CTF) polymer shells on Si nanoparticles, which could undergo pyrolysis to yield N-doped porous carbon coatings (Si@NPC). The N-doped carbon shell helped to realize a capacity of $1390 \mathrm{mAh} \mathrm{g}^{-1}$ at $0.5 \mathrm{~A} \mathrm{~g}^{-1}$, good cycling stability over 200 cycles at $1 \mathrm{~A} \mathrm{~g}^{-1}$ (107\% retention) and high-rate performance of about $420 \mathrm{mAh} \mathrm{g}^{-1}$ at $16 \mathrm{~A} \mathrm{~g}^{-1}$. The advantages of CTF as carbon coating precursor include high surface area, large pore volume and permanent porosity. The produced N-doped porous carbon coating could accommodate Si volume expansion, promote homogeneous SEI formation and realize good kinetics with its conductive properties.

\section{Monolayers}

The term monolayers refers to single layers of molecules on surfaces or at interfaces, and it is sometimes used interchangeably with the term self-assembled monolayers (SAMs). It is worth pointing out that neither term has strict definition, and in practice, they can both be used in a wide range of scenarios of interface-based layers of organic molecules. Classically, SAMs were developed as chemisorbed molecular single-layers on surfaces such as thiol molecules on gold substrate [72]. However, SAMs in recent developments have also included physisorbed organic molecule layers [73,74], which could create complicated patterns as nano-templates for bottom-up fabrication [75]. SAMs can also refer to layers of molecules on sphere surfaces such as nanoparticles [76]. Monolayers have a broader scope than SAMs, as the preparation of monolayers may not always strongly depend on self-assembly processes [77]. This section discusses monolayer-type coatings on silicon anodes, which are layers of organic molecules chemically bonded on the Si surface.

The large surface area and high reactivity of silicon (especially nano Si materials) pose challenges for Si electrode stability due to the unwanted reactions of organic electrolytes on the Si surface, and consequently, it is desirable to modify the silicon surface for tuning the contact between electrolyte and Si active materials [78]. For example, a parylene-based artificial SEI has recently been reported for engineering Si electrode interface [79]. The deposition could be uniformly controlled down to $30 \mathrm{~nm}$, leading to the formation of highly 
stable and elastic parylene layer to protect the Si electrodes. With the parylene layer, a high Si content of over $10 \mathrm{mg} \mathrm{cm}^{-2}$ has been achieved with a good capacity retention of $95.5 \%$ after 480 cycles. This is a representative example of $\mathrm{Si}$ interface modification with polymer materials. The functionalization of Si surfaces with monolayers has also been well established in the literature $[80,81]$. An extra organic layer on the $\mathrm{Si}$ surface could effectively protect the $\mathrm{Si}$ active material to improve cell performance [82,83]. Qian et al. [84] developed the electrolyte-phobic surface for the application of $\mathrm{Si}$ anodes. In this work, porous Si materials were prepared with metal-assisted chemical etching $(\mathrm{MaCE})$ and were further decorated with fluorinated monolayer-type coating via hydrosilylation reaction with $1 \mathrm{H}, 1 \mathrm{H}, 2 \mathrm{H}$-perfluoro-1-decene (PFD, and product denoted as pSi:PFD, see Figure 4a). In electrochemical testing, pSi:PFD presented a capacity of $1750 \mathrm{mAh} \mathrm{g}^{-1}$ after 100 cycles, while non-decorated Si (pSi) faded quickly in about 30 cycles. Additionally, the initial CEs of pSi:PFD and pSi were $88 \%$ and $\sim 60 \%$, respectively, showing mitigated side reactions on pSi:PFD. The improved performance was attributed to the porous structure of pSi:PFD that helped to self-accommodate Si volume expansion and also to the fluorinated layer that minimized the accessible electrode surface to bulk electrolyte (Figure $4 \mathrm{~b}$ ). Similarly, Jiang et al. [83] reported surface modification of Si nanoparticles with monolayers bearing organic cyclic ethylene carbonate groups. Such functionalized Si electrode materials allowed the formation of sturdy and regulated SEIs and reduced the parasitic reactions of the electrolyte at the electrode interface. This monolayer-coated Si anode demonstrated higher initial capacity and enhanced capacity retention in both half-cell and full-cell testing in comparison to pristine $\mathrm{Si}$ anode.

a
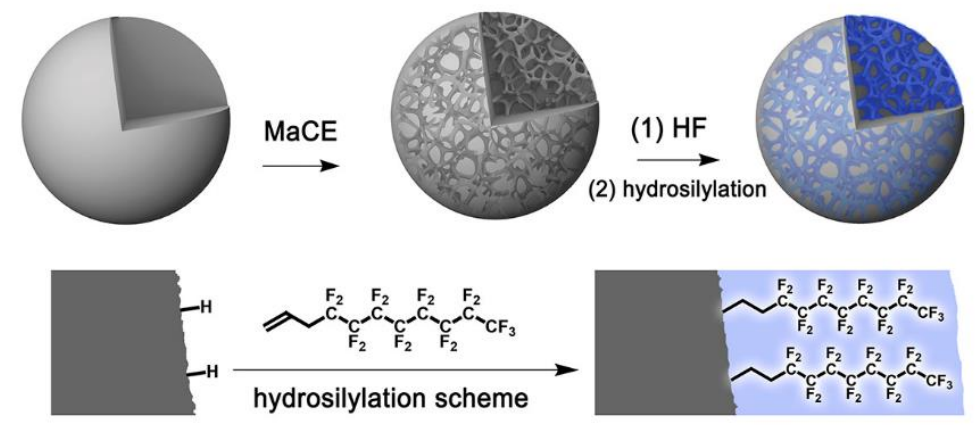

b
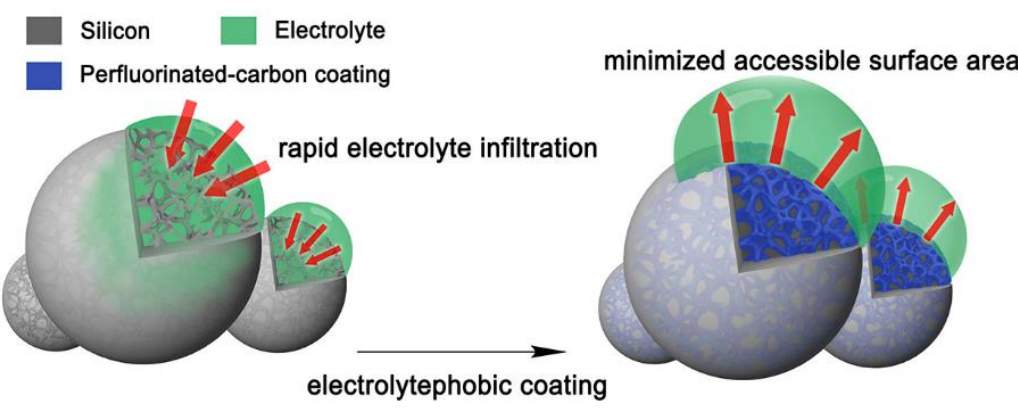

Figure 4. (a) Scheme of preparation of porous silicon nanoparticles decorated with fluorinated molecules. (b) Demonstration of the role of electrolytephobic coating (minimizing accessible surface area). Reprinted with permission from Ref. [84]. Copyright 2020 American Chemical Society.

Schulze et al. [85] systematically examined $\mathrm{Si}$ anodes with hydrophilic polyethylene oxide (PEO) and hydrophobic alkyl interfaces (Figure 5). The different molecular coatings on Si nanoparticles were prepared with the corresponding precursors on hydride-terminated $\mathrm{Si}$ surfaces via radical reaction. It was proposed that the dodecyl-based $\left(\mathrm{C}_{12}\right)$ hydrophobic interface inhibited both electron and $\mathrm{Li}^{+}$ion conduction, leading to negligible lithium storage capacity. In contrast, the hydrophilic PEO-based coating facilitated $\mathrm{Li}^{+}$transport across the Si interface with minimized parasitic reactions. Thick PEO coatings $(1.7-2.6 \mathrm{~nm})$ were found to cause electronic insulation of the Si materials from the conductive network, 
but PEO length (corresponding to coating thickness) would not strongly impact lithium consumption during SEI formation. Thus, the Si surface could not be sufficiently passivated simply by increasing the coating thickness.

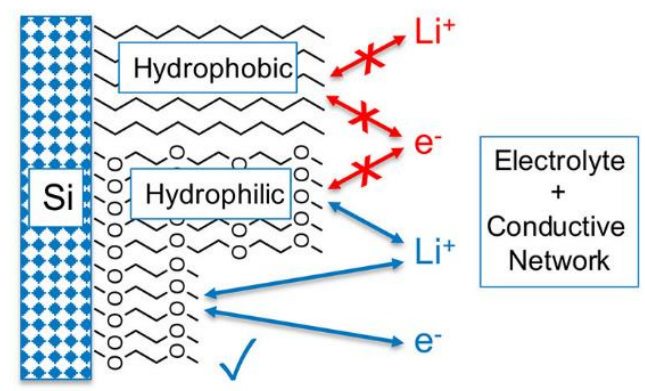

Figure 5. The electrical and ionic conductivity properties of different interface coatings on silicon. Reprinted with permission from Ref. [85]. Copyright 2021 American Chemical Society.

Reactive monolayers have also been reported for the application of Si anodes. Jiang et al. [86] developed epoxy monolayers on Si nanoparticles that were produced via silanization reaction between epoxy-trialkoxysilane precursors and silanol-enriched Si nanoparticles. The epoxy monolayer helped to improve the Si anode performance by forming covalent bonding with polyacrylic acid (PAA) binder and by preventing the parasitic reactions of electrolyte. Kang et al. [87] reported Si nanoparticles decorated with anime layers as Si anode materials. The amine layer was prepared by the reaction between the hydroxylterminated Si surface and the amine-bearing trimethoxysilane precursor. Instead of covalent bonding, the amine groups could form ionic bonding with the PAA binder, which realized stable long-term cycling for 400 cycles at $2.1 \mathrm{~A} \mathrm{~g}^{-1}$ with about $80 \%$ capacity retention. This is because the dynamic ionic bonding could better mitigate the capacity fading of the electrode caused by Si volume change. Amine-terminated SAM has also been reported for the application of $\mathrm{SiO}$ anode [88]. The amine-SAMs were grafted onto micron-size $\mathrm{SiO}$ particles, which further formed covalent bonding with the polyimide (PI) coating. This SAM/PI coating served to maintain the integrity of the active materials as well as the electrode and also helped to prevent side reactions for higher CE. A capacity of $873 \mathrm{mAh} \mathrm{g}^{-1}$ was maintained after 300 cycles at $1 \mathrm{~A} \mathrm{~g}^{-1}$.

\section{Conclusions}

Electrode surface engineering is an important research area for the practical application of Si-based LIBs. Molecular structures fabricated in a bottom-up manner is a facile strategy for constructing complex surface architectures using simple building blocks of organic molecules. MOFs, COFs and monolayers have been reported for the surface functionalization of $\mathrm{Si}$ anode materials. MOFs are produced by spontaneous coordination between metal ions and organic molecule linkers, yielding 2D or 3D porous structures. MOFs could allow good $\mathrm{Li}^{+}$conductivity across the Si surface, prevent parasitic electrolyte reactions and accommodate $\mathrm{Si}$ volume changes during lithiation and delithiation. These properties make MOFs a promising platform for interface optimization of Si anodes. In addition, MOFs could also serve as the precursors of porous carbon shells on Si anode. Such carbon structures could also function as a buffer layer for Si volume change and could provide good electrical and ionic conductivities as well. COFs are similar to MOFs but are fully constructed with organic molecules through rigid connections, which provide good mechanic strength to tolerate Si volume variation. Functionalized COFs could provide good ion conductivity and effective protection of Si surface. Monolayers are different than MOFs and COFs, as they are directly attached to the Si surface. The close covalent bonding of monolayers helps to realize highly efficient tuning of Si surface properties, where layers of few-nanometer thickness could dramatically change the surface properties based on the monolayer's molecular structures. In addition, reactive monolayers could also be applied 
to realize a higher level of the chemical complexity of the Si surface, and thus allow more favored interactions between $\mathrm{Si}$ active material and electrode composite.

It is worth noting that the number of reports on molecular structures on $\mathrm{Si}$ anodes is still limited, and there has not been wide exploration of different types of MOFs, COFs and monolayers for Si surface engineering in LIBs. On the other hand, there has been a tremendous number of such molecular structures developed in the literature with various properties and applications. The flexibility in structural properties is the key advantage of molecular architectures for surface modification of Si materials. Therefore, the toolbox of MOFs, COFs and monolayers can provide a rich and diverse content to assist future research of $\mathrm{Si}$ anode surface engineering.

Author Contributions: Writing, C.F.; Visualization, C.F.; Supervision, G.L. All authors have read and agreed to the published version of the manuscript.

Funding: This work was funded by the Assistant Secretary for Energy Efficiency, Vehicle Technologies Office of the U.S. Department of Energy and Lawrence Berkeley National Laboratory (LBNL) that was supported by the Director, Office of Science, Office of Basic Energy Sciences, of the US Department of Energy under contract No. DE-AC02-05CH11231.

Institutional Review Board Statement: Not applicable.

Informed Consent Statement: Not applicable.

Data Availability Statement: Not applicable.

Conflicts of Interest: The authors declare no conflict of interest.

\section{References}

1. McBrayer, J.D.; Rodrigues, M.-T.F.; Schulze, M.C.; Abraham, D.P.; Apblett, C.A.; Bloom, I.; Carroll, G.M.; Colclasure, A.M.; Fang, C.; Harrison, K.L.; et al. Calendar aging of silicon-containing batteries. Nat. Energy 2021, 6, 866-872. [CrossRef]

2. Yi, R.; Mao, Y.; Shen, Y.; Chen, L. Self-assembled monolayers for batteries. J. Am. Chem. Soc. 2021, 143, 12897-12912. [CrossRef]

3. Asenbauer, J.; Eisenmann, T.; Kuenzel, M.; Kazzazi, A.; Chen, Z.; Bresser, D. The success story of graphite as a lithium-ion anode material-Fundamentals, remaining challenges, and recent developments including silicon (oxide) composites. Sustain. Energy Fuels 2020, 4, 5387-5416. [CrossRef]

4. Lopez, C.V.; Maladeniya, C.P.; Smith, R.C. Lithium-sulfur batteries: Advances and trends. Electrochem 2020, 1, 226-259. [CrossRef]

5. Liu, Z.; He, X.; Fang, C.; Camacho-Forero, L.E.; Zhao, Y.; Fu, Y.; Feng, J.; Kostecki, R.; Balbuena, P.B.; Zhang, J.; et al. Reversible crosslinked polymer binder for recyclable lithium sulfur batteries with high performance. Adv. Funct. Mater. 2020, $30,2003605$. [CrossRef]

6. Li, Z.; Fang, C.; Qian, C.; Zhou, S.; Song, X.; Ling, M.; Liang, C.; Liu, G. Polyisoprene captured sulfur nanocomposite materials for high-areal-capacity lithium sulfur battery. ACS Appl. Polym. Mater. 2019, 1, 1965-1970. [CrossRef]

7. Fang, C.; Zhang, G.; Lau, J.; Liu, G. Recent advances in polysulfide mediation of lithium-sulfur batteries via facile cathode and electrolyte modification. APL Mater. 2019, 7, 080902. [CrossRef]

8. Zhao, Y.; Fang, C.; Zhang, G.; Hubble, D.; Nallapaneni, A.; Zhu, C.; Zhao, Z.; Liu, Z.; Lau, J.; Fu, Y.; et al. A Micelle electrolyte enabled by fluorinated ether additives for polysulfide suppression and Li metal stabilization in Li-S battery. Front. Chem. 2020, 8, 484. [CrossRef]

9. Li, T.; Bai, X.; Gulzar, U.; Bai, Y.-J.; Capiglia, C.; Deng, W.; Zhou, X.; Liu, Z.; Feng, Z.; Proietti Zaccaria, R. A comprehensive understanding of lithium-sulfur battery technology. Adv. Funct. Mater. 2019, 29, 1901730. [CrossRef]

10. Phadatare, M.; Patil, R.; Blomquist, N.; Forsberg, S.; Örtegren, J.; Hummelgård, M.; Meshram, J.; Hernández, G.; Brandell, D.; Leifer, K.; et al. Silicon-nanographite aerogel-based anodes for high performance lithium ion batteries. Sci. Rep. 2019, 9, 14621. [CrossRef]

11. Zhou, S.; Fang, C.; Song, X.; Liu, G. The influence of compact and ordered carbon coating on solid-state behaviors of silicon during electrochemical processes. Carbon Energy 2020, 2, 143-150. [CrossRef]

12. He, S.; Huang, S.; Wang, S.; Mizota, I.; Liu, X.; Hou, X. Considering critical factors of silicon/graphite anode materials for practical high-energy lithium-ion battery applications. Energy Fuels 2021, 35, 944-964. [CrossRef]

13. Fang, C.; Xiao, H.; Zheng, T.; Bai, H.; Liu, G. Organic solvent free process to fabricate high performance silicon/graphite composite anode. J. Compos. Sci. 2021, 5, 188. [CrossRef]

14. Chae, S.; Choi, S.-H.; Kim, N.; Sung, J.; Cho, J. Integration of graphite and silicon anodes for the commercialization of high-energy lithium-ion batteries. Angew. Chem. Int. Ed. 2020, 59, 110-135. [CrossRef]

15. Zamfir, M.R.; Nguyen, H.T.; Moyen, E.; Lee, Y.H.; Pribat, D. Silicon nanowires for Li-based battery anodes: A review. J. Mater. Chem. A 2013, 1, 9566-9586. [CrossRef] 
16. Li, S.; Liu, Y.-M.; Zhang, Y.-C.; Song, Y.; Wang, G.-K.; Liu, Y.-X.; Wu, Z.-G.; Zhong, B.-H.; Zhong, Y.-J.; Guo, X.-D. A review of rational design and investigation of binders applied in silicon-based anodes for lithium-ion batteries. J. Power Sources 2021, 485, 229331. [CrossRef]

17. Yuda, A.P.; Koraag, P.Y.E.; Iskandar, F.; Wasisto, H.S.; Sumboja, A. Advances of the top-down synthesis approach for highperformance silicon anodes in Li-ion batteries. J. Mater. Chem. A 2021, 9, 18906-18926. [CrossRef]

18. Fang, C.; Tran, T.-N.; Zhao, Y.; Liu, G. Electrolyte decomposition and solid electrolyte interphase revealed by mass spectrometry. Electrochim. Acta 2021, 399, 139362. [CrossRef]

19. Jia, H.; Li, X.; Song, J.; Zhang, X.; Luo, L.; He, Y.; Li, B.; Cai, Y.; Hu, S.; Xiao, X.; et al. Hierarchical porous silicon structures with extraordinary mechanical strength as high-performance lithium-ion battery anodes. Nat. Commun. 2020, 11, 1474. [CrossRef] [PubMed]

20. Zuo, X.; Zhu, J.; Müller-Buschbaum, P.; Cheng, Y.-J. Silicon based lithium-ion battery anodes: A chronicle perspective review. Nano Energy 2017, 31, 113-143. [CrossRef]

21. Franco Gonzalez, A.; Yang, N.-H.; Liu, R.-S. Silicon anode design for lithium-ion batteries: Progress and perspectives. J. Phys. Chem. C 2017, 121, 27775-27787. [CrossRef]

22. Zhang, Y.; Du, N.; Yang, D. Designing superior solid electrolyte interfaces on silicon anodes for high-performance lithium-ion batteries. Nanoscale 2019, 11, 19086-19104. [CrossRef] [PubMed]

23. Hopkins, E.J.; Frisco, S.; Pekarek, R.T.; Stetson, C.; Huey, Z.; Harvey, S.; Li, X.; Key, B.; Fang, C.; Liu, G.; et al. Examining CO 2 as an additive for solid electrolyte interphase formation on silicon anodes. J. Electrochem. Soc. 2021, 168, 030534. [CrossRef]

24. Fang, C.; Lau, J.; Hubble, D.; Khomein, P.; Dailing, E.A.; Liu, Y.; Liu, G. Large-molecule decomposition products of electrolytes and additives revealed by on-electrode chromatography and MALDI. Joule 2021, 5, 415-428. [CrossRef]

25. Shen, T.; Yao, Z.; Xia, X.; Wang, X.; Gu, C.; Tu, J. Rationally designed silicon nanostructures as anode material for lithium-ion batteries. Adv. Eng. Mater. 2018, 20, 1700591. [CrossRef]

26. Lee, S.H.; Lee, J.H.; Nam, D.H.; Cho, M.; Kim, J.; Chanthad, C.; Lee, Y. Epoxidized natural rubber/chitosan network binder for silicon anode in lithium-ion battery. ACS Appl. Mater. Interfaces 2018, 10, 16449-16457. [CrossRef]

27. Liu, Z.; Fang, C.; He, X.; Zhao, Y.; Xu, H.; Lei, J.; Liu, G. In situ-formed novel elastic network binder for a silicon anode in lithium-ion batteries. ACS Appl. Mater. Interfaces 2021, 13, 46518-46525. [CrossRef]

28. Jiang, C.; Xiang, L.; Miao, S.; Shi, L.; Xie, D.; Yan, J.; Zheng, Z.; Zhang, X.; Tang, Y. Flexible interface design for stress regulation of a silicon anode toward highly stable dual-ion batteries. Adv. Mater. 2020, 32, 1908470. [CrossRef] [PubMed]

29. Huang, G.; Han, J.; Lu, Z.; Wei, D.; Kashani, H.; Watanabe, K.; Chen, M. Ultrastable silicon anode by three-dimensional nanoarchitecture design. ACS Nano 2020, 14, 4374-4382. [CrossRef]

30. Li, Z.; Zhang, Y.; Liu, T.; Gao, X.; Li, S.; Ling, M.; Liang, C.; Zheng, J.; Lin, Z. Silicon anode with high initial coulombic efficiency by modulated trifunctional binder for high-areal-capacity lithium-ion batteries. Adv. Energy Mater. 2020, 10, 1903110. [CrossRef]

31. Zhang, L.; Wang, C.; Dou, Y.; Cheng, N.; Cui, D.; Du, Y.; Liu, P.; Al-Mamun, M.; Zhang, S.; Zhao, H. A Yolk-shell structured silicon anode with superior conductivity and high tap density for full lithium-ion batteries. Angew. Chem. Int. Ed. 2019, 58, 8824-8828. [CrossRef] [PubMed]

32. Li, P.; Kim, H.; Myung, S.-T.; Sun, Y.-K. Diverting exploration of silicon anode into practical way: A review focused on silicon-graphite composite for lithium ion batteries. Energy Storage Mater. 2021, 35, 550-576. [CrossRef]

33. Zhou, S.; Fang, C.; Song, X.; Liu, G. Highly ordered carbon coating prepared with polyvinylidene chloride precursor for high-performance silicon anodes in lithium-ion batteries. Batter. Supercaps 2021, 4, 240-247. [CrossRef]

34. Geng, K.; He, T.; Liu, R.; Dalapati, S.; Tan, K.T.; Li, Z.; Tao, S.; Gong, Y.; Jiang, Q.; Jiang, D. Covalent organic frameworks: Design, synthesis, and functions. Chem. Rev. 2020, 120, 8814-8933. [CrossRef]

35. Baumann, A.E.; Burns, D.A.; Liu, B.; Thoi, V.S. Metal-organic framework functionalization and design strategies for advanced electrochemical energy storage devices. Commun. Chem. 2019, 2, 86. [CrossRef]

36. Veerbeek, J.; Huskens, J. Applications of monolayer-functionalized h-terminated silicon surfaces: A review. Small Methods 2017, 1, 1700072. [CrossRef]

37. Cai, G.; Yan, P.; Zhang, L.; Zhou, H.-C.; Jiang, H.-L. Metal-organic framework-based hierarchically porous materials: Synthesis and applications. Chem. Rev. 2021, 121, 12278-12326. [CrossRef]

38. Zhong, M.; Kong, L.; Li, N.; Liu, Y.-Y.; Zhu, J.; Bu, X.-H. Synthesis of MOF-derived nanostructures and their applications as anodes in lithium and sodium ion batteries. Coord. Chem. Rev. 2019, 388, 172-201. [CrossRef]

39. Xie, L.S.; Skorupskii, G.; Dincă, M. Electrically conductive metal-organic frameworks. Chem. Rev. 2020, 120, 8536-8580. [CrossRef]

40. Zhou, H.-C.; Long, J.R.; Yaghi, O.M. Introduction to metal-organic frameworks. Chem. Rev. 2012, 112, 673-674. [CrossRef]

41. Cohen, S.M. Postsynthetic methods for the functionalization of metal-organic frameworks. Chem. Rev. 2012, 112, 970-1000. [CrossRef]

42. Jiang, Y.; Zhao, H.; Yue, L.; Liang, J.; Li, T.; Liu, Q.; Luo, Y.; Kong, X.; Lu, S.; Shi, X.; et al. Recent advances in lithium-based batteries using metal organic frameworks as electrode materials. Electrochem. Commun. 2021, 122, 106881. [CrossRef]

43. Han, Y.; Qi, P.; Zhou, J.; Feng, X.; Li, S.; Fu, X.; Zhao, J.; Yu, D.; Wang, B. Metal-Organic Frameworks (MOFs) as sandwich coating cushion for silicon anode in lithium ion batteries. ACS Appl. Mater. Interfaces 2015, 7, 26608-26613. [CrossRef] [PubMed]

44. Yoon, T.; Bok, T.; Kim, C.; Na, Y.; Park, S.; Kim, K.S. Mesoporous silicon hollow nanocubes derived from metal-organic framework template for advanced lithium-ion battery anode. ACS Nano 2017, 11, 4808-4815. [CrossRef] 
45. Malik, R.; Loveridge, M.J.; Williams, L.J.; Huang, Q.; West, G.; Shearing, P.R.; Bhagat, R.; Walton, R.I. Porous metal-organic frameworks for enhanced performance silicon anodes in lithium-ion batteries. Chem. Mater. 2019, 31, 4156-4165. [CrossRef]

46. Nazir, A.; Le, H.T.T.; Min, C.-W.; Kasbe, A.; Kim, J.; Jin, C.-S.; Park, C.-J. Coupling of a conductive Ni3(2,3,6,7,10,11hexaiminotriphenylene) 2 metal-organic framework with silicon nanoparticles for use in high-capacity lithium-ion batteries. Nanoscale 2020, 12, 1629-1642. [CrossRef]

47. Nazir, A.; Le, H.T.T.; Kasbe, A.; Park, C.-J. Si nanoparticles confined within a conductive 2D porous Cu-based metal-organic framework (Cu3(HITP)2) as potential anodes for high-capacity Li-ion batteries. Chem. Eng. J. 2021, 405, 126963. [CrossRef]

48. Yu, Y.; Yue, C.; Lin, X.; Sun, S.; Gu, J.; He, X.; Zhang, C.; Lin, W.; Lin, D.; Liao, X.; et al. ZIF-8 Cooperating in TiN/Ti/Si Nanorods as Efficient Anodes in Micro-Lithium-Ion-Batteries. ACS Appl. Mater. Interfaces 2016, 8, 3992-3999. [CrossRef] [PubMed]

49. Yu, Y.; Yue, C.; Han, Y.; Zhang, C.; Zheng, M.; Xu, B.; Lin, S.; Li, J.; Kang, J. Si nanorod arrays modified with metal-organic segments as anodes in lithium ion batteries. RSC Adv. 2017, 7, 53680-53685. [CrossRef]

50. Bai, Y.; Zeng, M.; Wu, X.; Zhang, Y.; Wen, J.; Li, J. Three-dimensional cage-like Si@ZIF-67 core-shell composites for highperformance lithium storage. Appl. Surf. Sci. 2020, 510, 145477. [CrossRef]

51. Gao, R.; Tang, J.; Yu, X.; Tang, S.; Ozawa, K.; Sasaki, T.; Qin, L.-C. In situ synthesis of MOF-derived carbon shells for silicon anode with improved lithium-ion storage. Nano Energy 2020, 70, 104444. [CrossRef]

52. Li, Q.; Wang, Y.; Yu, J.; Yuan, M.; Tan, Q.; Zhong, Z.; Su, F. High-performance Si-Containing anode materials in lithium-ion batteries: A superstructure of Si@Co-NC composite works effectively. Green Energy Environ. 2020. [CrossRef]

53. Jin, D.; Yang, X.; Ou, Y.; Rao, M.; Zhong, Y.; Zhou, G.; Ye, D.; Qiu, Y.; Wu, Y.; Li, W. Thermal pyrolysis of Si@ZIF-67 into Si@N-doped CNTs towards highly stable lithium storage. Sci. Bull. 2020, 65, 452-459. [CrossRef]

54. Liu, N.; Liu, J.; Jia, D.; Huang, Y.; Luo, J.; Mamat, X.; Yu, Y.; Dong, Y.; Hu, G. Multi-core yolk-shell like mesoporous double carbon-coated silicon nanoparticles as anode materials for lithium-ion batteries. Energy Storage Mater. 2019, 18, 165-173. [CrossRef]

55. Qiao, Y.; Hu, Y.; Liu, W.; Zhang, H.; Shang, H.; Qu, M.; Peng, G.; Xie, Z. Synergistic carbon coating of MOF-derived porous carbon and CNTs on silicon for high performance lithium-ion batteries. J. Electroanal. Chem. 2021, 888, 115014. [CrossRef]

56. Qiao, Y.-J.; Zhang, H.; Hu, Y.-X.; Li, W.-P.; Liu, W.-J.; Shang, H.-M.; Qu, M.-Z.; Peng, G.-C.; Xie, Z.-W. A chain-like compound of Si@CNT nanostructures and MOF-derived porous carbon as an anode for Li-ion batteries. Int. J. Miner. Metall. Mater. 2021, 28, 1611-1620. [CrossRef]

57. Han, Y.; Qi, P.; Feng, X.; Li, S.; Fu, X.; Li, H.; Chen, Y.; Zhou, J.; Li, X.; Wang, B. In situ growth of MOFs on the surface of Si nanoparticles for highly efficient lithium storage: Si@MOF nanocomposites as anode materials for lithium-ion batteries. ACS Appl. Mater. Interfaces 2015, 7, 2178-2182. [CrossRef] [PubMed]

58. Song, Y.; Zuo, L.; Chen, S.; Wu, J.; Hou, H.; Wang, L. Porous Nano-Si/carbon derived from zeolitic imidazolate frameworks@Nano$\mathrm{Si}$ as anode materials for lithium-ion batteries. Electrochim. Acta 2015, 173, 588-594. [CrossRef]

59. Wei, Q.; Chen, Y.-M.; Hong, X.-J.; Song, C.-L.; Yang, Y.; Si, L.-P.; Zhang, M.; Cai, Y.-P. Saclike-silicon nanoparticles anchored in ZIF-8 derived spongy matrix as high-performance anode for lithium-ion batteries. J. Colloid Interface Sci. 2020, 565, 315-325. [CrossRef]

60. Wei, Q.; Chen, Y.-M.; Hong, X.-J.; Song, C.-L.; Yang, Y.; Si, L.-P.; Zhang, M.; Cai, Y.-P. Novel bread-like nitrogen-doped carbon anchored nano-silicon as high-stable anode for lithium-ion batteries. Appl. Surf. Sci. 2020, 511, 145609. [CrossRef]

61. Majeed, M.K.; Ma, G.; Cao, Y.; Mao, H.; Ma, X.; Ma, W. Metal-organic frameworks-derived mesoporous Si/SiOx@NC nanospheres as a long-lifespan anode material for lithium-ion batteries. Chem. Eur. J. 2019, 25, 11991-11997. [CrossRef]

62. Zhang, K.; Mao, H.; Gu, X.; Song, C.; Yang, J.; Qian, Y. ZIF-derived cobalt-containing N-doped carbon-coated SiOx nanoparticles for superior lithium storage. ACS Appl. Mater. Interfaces 2020, 12, 7206-7211. [CrossRef] [PubMed]

63. Feng, L.; Han, X.; Su, X.; Pang, B.; Luo, Y.; Hu, F.; Zhou, M.; Tao, K.; Xia, Y. Metal-organic frameworks derived porous carbon coated $\mathrm{SiO}$ composite as superior anode material for lithium ion batteries. J. Alloys Compd. 2018, 765, 512-519. [CrossRef]

64. Wang, K.; Pei, S.; He, Z.; Huang, L.-A.; Zhu, S.; Guo, J.; Shao, H.; Wang, J. Synthesis of a novel porous silicon microsphere@carbon core-shell composite via in situ MOF coating for lithium ion battery anodes. Chem. Eng. J. 2019, 356, 272-281. [CrossRef]

65. Wu, F.; Wang, H.; Shi, J.; Yan, Z.; Song, S.; Peng, B.; Zhang, X.; Xiang, Y. Surface modification of silicon nanoparticles by an “Ink” layer for advanced lithium ion batteries. ACS Appl. Mater. Interfaces 2018, 10, 19639-19648. [CrossRef]

66. Wang, Q.; Guo, C.; He, J.; Yang, S.; Liu, Z.; Wang, Q. Fe2O3/C-modified Si nanoparticles as anode material for high-performance lithium-ion batteries. J. Alloys Compd. 2019, 795, 284-290. [CrossRef]

67. Xu, Y.; Sun, X.; Wei, C.; Liang, G.; Huang, Y.; Li, R.; He, Q. A novel Si/Ag@PM@MIL-100 porous double-shell anode materials prepared by in-situ growth with MOF coatings. J. Mater. Sci. Mater. Electron. 2020, 31, 1524-1534. [CrossRef]

68. Huang, N.; Wang, P.; Jiang, D. Covalent organic frameworks: A materials platform for structural and functional designs. Nat. Rev. Mater. 2016, 1, 16068. [CrossRef]

69. Chen, D.; Huang, S.; Zhong, L.; Wang, S.; Xiao, M.; Han, D.; Meng, Y. In situ preparation of thin and rigid COF film on Li anode as artificial solid electrolyte interphase layer resisting Li dendrite puncture. Adv. Funct. Mater. 2020, 30, 1907717. [CrossRef]

70. Ai, Q.; Fang, Q.; Liang, J.; Xu, X.; Zhai, T.; Gao, G.; Guo, H.; Han, G.; Ci, L.; Lou, J. Lithium-conducting covalent-organicframeworks as artificial solid-electrolyte-interphase on silicon anode for high performance lithium ion batteries. Nano Energy 2020, 72, 104657. [CrossRef]

71. Zhu, J.; Yang, J.; Xu, Z.; Wang, J.; Nuli, Y.; Zhuang, X.; Feng, X. Silicon anodes protected by a nitrogen-doped porous carbon shell for high-performance lithium-ion batteries. Nanoscale 2017, 9, 8871-8878. [CrossRef] 
72. Xue, Y.; Li, X.; Li, H.; Zhang, W. Quantifying thiol-gold interactions towards the efficient strength control. Nat. Commun. 2014, 5, 4348. [CrossRef]

73. Velpula, G.; Takeda, T.; Adisoejoso, J.; Inukai, K.; Tahara, K.; Mali, K.S.; Tobe, Y.; De Feyter, S. On the formation of concentric 2D multicomponent assemblies at the solution-solid interface. Chem. Commun. 2017, 53, 1108-1111. [CrossRef] [PubMed]

74. He, J.; Fang, C.; Shelp, R.A.; Zimmt, M.B. Tracking invisible transformations of physisorbed monolayers: LDI-TOF and MALDITOF mass spectrometry as complements to STM imaging. Langmuir 2017, 33, 459-467. [CrossRef]

75. Fang, C.; Zhu, H.; Chen, O.; Zimmt, M.B. Reactive two-component monolayers template bottom-up assembly of nanoparticle arrays on HOPG. Chem. Commun. 2018, 54, 8056-8059. [CrossRef]

76. Colangelo, E.; Comenge, J.; Paramelle, D.; Volk, M.; Chen, Q.; Lévy, R. Characterizing self-assembled monolayers on gold nanoparticles. Bioconjugate Chem. 2017, 28, 11-22. [CrossRef]

77. Eves, B.J.; Lopinski, G.P. Formation of organic monolayers on silicon via gas-phase photochemical reactions. Langmuir 2006, 22, 3180-3185. [CrossRef]

78. Ashuri, M.; He, Q.; Shaw, L.L. Silicon as a potential anode material for Li-ion batteries: Where size, geometry and structure matter. Nanoscale 2016, 8, 74-103. [CrossRef]

79. Harpak, N.; Davidi, G.; Patolsky, F. Breathing parylene-based nanothin artificial SEI for highly-stable long life three-dimensional silicon lithium-ion batteries. Chem. Eng. J. 2022, 429, 132077. [CrossRef]

80. Voicu, R.; Boukherroub, R.; Bartzoka, V.; Ward, T.; Wojtyk, J.T.C.; Wayner, D.D.M. Formation, characterization, and chemistry of undecanoic acid-terminated silicon surfaces: Patterning and immobilization of DNA. Langmuir 2004, 20, 11713-11720. [CrossRef] [PubMed]

81. Böcking, T.; Kilian, K.A.; Gaus, K.; Gooding, J.J. Single-step DNA immobilization on antifouling self-assembled monolayers covalently bound to silicon (111). Langmuir 2006, 22, 3494-3496. [CrossRef]

82. Min, J.-H.; Bae, Y.-S.; Kim, J.-Y.; Kim, S.S.; Song, S.-W. Self-organized Artificial SEI for Improving the Cycling Ability of Silicon-based Battery Anode Materials. Bull. Korean Chem. Soc. 2013, 34, 1296-1299. [CrossRef]

83. Jiang, S.; Yang, Z.; Liu, Y.; Johnson, N.; Bloom, I.; Zhang, L.; Zhang, Z. Engineering the Si anode interface via particle surface modification: Embedded organic carbonates lead to enhanced performance. ACS Appl. Energy Mater. 2021, 4, 8193-8200. [CrossRef]

84. Qian, C.; Zhao, J.; Sun, Y.; Lee, H.R.; Luo, L.; Makaremi, M.; Mukherjee, S.; Wang, J.; Zu, C.; Xia, M.; et al. Electrolyte-phobic surface for the next-generation nanostructured battery electrodes. Nano Lett. 2020, 20, 7455-7462. [CrossRef]

85. Schulze, M.C.; Carroll, G.M.; Martin, T.R.; Sanchez-Rivera, K.; Urias, F.; Neale, N.R. Hydrophobic versus hydrophilic interfacial coatings on silicon nanoparticles teach us how to design the solid electrolyte interphase in silicon-based Li-Ion battery anodes. ACS Appl. Energy Mater. 2021, 4, 1628-1636. [CrossRef]

86. Jiang, S.; Hu, B.; Sahore, R.; Zhang, L.; Liu, H.; Zhang, L.; Lu, W.; Zhao, B.; Zhang, Z. Surface-functionalized silicon nanoparticles as anode material for Lithium-Ion battery. ACS Appl. Mater. Interfaces 2018, 10, 44924-44931. [CrossRef]

87. Kang, S.; Yang, K.; White, S.R.; Sottos, N.R. Silicon composite electrodes with dynamic ionic bonding. Adv. Energy Mater. 2017, 7, 1700045. [CrossRef]

88. Tan, T.; Lee, P.-K.; Zettsu, N.; Teshima, K.; Yu, D.Y.W. Highly stable lithium-ion battery anode with polyimide coating anchored onto micron-size silicon monoxide via self-assembled monolayer. J. Power Sources 2020, 453, 227874. [CrossRef] 